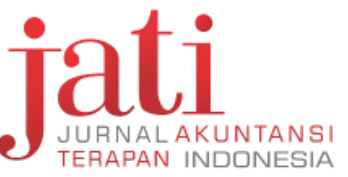

Jati: Jurnal Akuntansi Terapan Indonesia Vol 2 No 1 Hal 1-7 Maret 2019

\title{
Analisis Prosedur dan Perhitungan Bagi Hasil Pembiayaan Musyarakah di BMT Batik Mataram Wirobrajan Yogyakarta
}

http://journal.umy.ac.id/index.php/jati

DOI: 10.18196/jati.020111

\section{DATA ARTIKEL:}

Diterima: 14 Mei 2019

Direviu: 16 Juli 2019

Direvisi: 22 Juli 2019

Disetujui: 1 Agustus 2019

\author{
FARIDA PRASEPTYANINGRUM*, DESI SUSILAWATI, LINDA \\ KUSUMASTUTI WARDANA \\ Universitas Muhammadiyah Yogyakarta \\ *Email korespodensi : farida.ningrum96@gmail.com
}

TOPIK ARTIKEL:

Akuntansi Syariah

\begin{abstract}
ABSTRAK: Penelitian ini bertujuan untuk mengetahui kesuaian pelaksanaan pembiayaan musyarakah di BMT Batik Mataram wirobrajan dengan DSN-MUI bagaimana pelaksanaan prosedur dan perhitungan bagi hasil pembiayaan musyarakah di BMT Batik Mataram Wirobrajan Yogyakarta. Kemudian dilakukan analisis terhadap penerapan prosedur dan perhitungan bagi hasil pembiayaan musyarakah di BMT Batik Mataram apakah sudah sesuai atau belum dengan peraturan syariah sesuai dengan DSN-MUI fatwa No.08/DSN-MUI/IV/2000. Metode yang digunakan dalam penelitian ini adalah deskriptif analisis, yaitu metode yang digunakan untuk menganalisis suatu hasil penelitian berdasarkan fakta yang tampak sebagaimana adanya. Pengumpulan data dilakukan dengan cara wawancara dan observasi terhadap pihak BMT. Data terdiri dari data primer dan data sekunder. Data primer berupa hasil wawancara dan observasi sedangkan data sekunder berupa rincian angsuran nasabah pembiayaan musyarakah usaha untung dan usaha rugi. Hasil analisis menunjukkan terdapat ketidaksesuaian dalam prosedur yang dilaksanakan yaitu ketika terjadi kerugian menurut DSN-MUI kerugian tersebut harus ditanggung kedua mitra sesuai dengan porsi modal masig-masing, namun pada BMT Batik Mataram dilakukan reschedulling dengan memberi keringanan jumlah angsuran dan perpanjangan waktu tempo pengembalian pembiayaan. Dan pada perhitungan bagi hasil menurut DSN-MUI harus didasarkan pada keuntungan setiap periodenya dari usaha musyarakah, namun pada BMT batik Mataram bagi hasil didasarkan pada besaran pinjaman pokok.
\end{abstract}

Kata Kunci: Pembiayaan Musyarakah, Fatwa DSN-MUI fatwa No.08/DSN-MUI/IV/2000, Prosedur Pelaksanaan, dan Perhitungan Bagi Hasil

ABSTRACT: This research aimed to acknowledge the procedure and calculation of profit sharing for musyarakah financing at BMT Batik Mataram Wirobrajan Yogyakarta in accordance with DSN-MUI fatwa No.08/DSN. $\mathrm{MUI} / \mathrm{IV} / 2000$. The method that used in this research is descriptive analysis, used to analyze the result according to the real impact in the field. The interview and observation used for collecting data from BMT. Data consists of primary and secondary data. The primary data is in the form of interview and observation, meanwhile the secondary data is in the form of details of customer installments, musyarakah financing, profit and loss business. The result shows that there is a discrepancy procedure when loss happens according to DSN-MUI. The both side should take the responsibility with their own fund portions with rescheduling of BMT Batik Mataram by diminish the instalment payment and extending the time return. In calculation of profit sharing according to DSN-MUI should be based on the profit in every period from musyarakah, but the sharing profit of BMT Batik Mataram based on the amount of principal loan.

Keywords: Musyarakah financing, Fatwa DSN-MUI fatwa No.08/DSN-MUI/IV/2000, implementation procedure, and calculation of profit sharing.

SITASI ARTIKEL: Praseptyaningrum.F. (2019). Analisis Penerapan Fatwa DSN-MUI NO.08/DSN-MUI/IV/2000 Tentang Prosedur Dan Perhitungan Bagi Hasil Pembiayaan Musyarakah di BMT Batik Mataram Wirobrajan Yogyakarta. Jati: Jurnal Akuntansi Terapan Indonesia, 2(1), 1-7 


\section{PENDAHULUAN}

Seiring dengan kebutuhan masyarakat yang semakin meningkat, sebagian dari masyarakat tersebut membutuhkan lembaga keuangan dalam pemenuhan kebutuhan, seperti modal usaha, konsumsi, pendidikan, dan lain sebagainya. Lembaga keuangan merupakan lembaga perantara keuangan (financial intermediaries) sebagai perantara pendukung yang amat vital untuk menjunjung kelancaran perekonomian (Wiwoho, 2014). Menurut Hestanto (2016) lembaga keuangan dibagi menjadi dua yaitu, lembaga keuangan perbankan dan lembaga keuangan non perbankan. Lembaga perbankan adalah Bank Umum, Bank Syariah, BPR, dan BPR Syariah. Sedangkan lembaga keuangan non perbankan adalah BMT/KJKS/UJKS, KSP/USP, Pega-daian, dan Asuransi.

BMT sebagai lembaga keuangan non perbankan lebih banyak berjalan untuk anggotanya sendiri, dan kalangan kecil menengah. Sriyana (2013) mengemukakan bahwa peran BMT dalam mengurangi angka kemiskinan adalah sangat strategis, mengingat lembaga perbankan belum mampu menyentuh masyarakat akar rumput yang meliputi fakir, miskin dan kaum dhuafa. BMT merupakan koperasi jasa keuangan yang diartikan sebagai koperasi yang meyelenggarakan dan mengatur jasa keuangan selain bank untuk masyarakat (Agustha, 2014). Hal tersebut merupakan dua dari kelebihan bahwa BMT memberikan pelayanan terbaik bagi masyarakat yang belum mampu menyentuh lembaga keuangan perbankan.

Riadi (2014) BMT merupakan kependekan dari Balai Usaha Mandiri Terpadu atau Baitul Maal wa Tamwil atau biasa disebut BMT. Adapun berbagai fungsi BMT yang pertama; Baitut Tamwil (rumah pengembangan harta), yaitu fungsi untuk mengembangkan usaha-usaha produktif dan investasi seperti menabung dan pemberian pembiayaan kegiatan ekonomi; kedua, Baitul maal (rumah harta) yaitu fungsi untuk menerima titipan dana zakat, infak dan sedekah serta untuk mengoptimalkan distribusinya sesuai dengan peraturan dan amanah yang harus dipenuhi.

Beberapa produk yang dikeluarkan oleh BMT sama halnya dengan produk yang dikeluarkan oleh bank Syariah, salah satunya adalah produk pembiayaan musyarakah. Dewan Syariah Nasional mengeluarkan fatwa No.08/DSN-MUI/IV/2000 tentang pembiayaan musyarakah dan menjelaskan pertimbangan dikeluarkannya pembiayaan tersebut yaitu: (a) upaya untuk memenuhi kebutuhan, masyarakat tidak jarang harus melibatkan pihak ketiga antara lain dengan menggunakan pembiayaan musyarakah, yaitu pembiayaan yang berdasarkan akad kerjasama antara dua belah pihak atau lebih untuk suatu usaha tertentu, masing- masing pihak menyediakan dana, kemudian keuntungan dan resiko akan ditanggung bersama-sama; (b) pembiayaan musyarakah memiliki ke-unggulan yaitu dalam kebersamaan dan keadilan, baik dalam keuntungan atau resiko kerugian yang dilakukan Lembaga Keuangan Syariah (LKS); (c) cara tersebut agar dilakukan sesuai dengan prinsip Syariah Islam, maka DSNMUI perlu menetapkan fatwa tentang musyarakah untuk dijadikan pedoman LKS."

Salah satu firman Allah di dalam Al-Qur'an juga menjelaskan bahwa diperbolehkan adanya pembiayaan musyarakah salah satunya adalah firman Allah tersebut adalah QS. Shad [38]: 24:

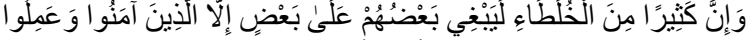

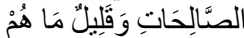

"Dan sesungguhnya kebanyakan dari orang-orang yang bersyarikat itu sebagian dari mereka berbuat zalim kepada sebagian lain, kecuali orang yang beriman dan mengerjakan amal shaleh; dan amat sedikitlah mereka ini...." (QS. Shad [38]: 24).

BMT Batik Mataram adalah salah satu koperasi yang melakukan kegiatanya dengan prinsip syariah, sehingga dalam pelaksanaanya harus tunduk pada aturan Lembaga Keuangan Syariah. Koperasi institut keuangan Islam terutama didasarkan pada prinsip PLS (profit-and-loss-sharing bagi untung dan rugi). Disebutkan juga prinsip bagi hasil ini dalam keuangan Islam sangat dianjurkan dan merupakan solusi yang baik untuk mengatasi alokasi dana yang terbatas, baik dana pinjaman atau tabungan dengan tujuan bisnis tercapai.

Pembiayaan yang paling banyak diajukan oleh nasabah BMT Batik Mataram adalah musyarakah. Dalam hal ini perlu dipastikan bahwa pembiayaan musyarakah tersebut sudah sesuai dengan aturan yang ada, agar memperoleh kenyamanan dan ketentraman dari pihak BMT ataupun nasabah. Tidak hanya bentuk produk yang ditawarkannya telah sesuai dengan syariah, melainkan pola hubungan yang dibangun antara bank Syariah (Lembaga Keuangan Syariah) dengan nasabah sebagai konsumen pengguna jasa perbankan pun harus menegakkan nilai-nilai syariah (Nugraheni, 2010). Oleh karena itu penulis akan menggali lebih dalam dari penerapan fatwa No.08/DSN-MUI/IV/2000 terhadap pelaksanaan pembiayaan musyarakah di BMT Batik Mataram Wirobrajan. Penulis akan melakukan penelitin yang berjudul "Analisis Prosedur dan Perhitungan Bagi Hasil Pembiayaan mu-syarakah di BMT Batik Mataram Wirobrajan Yogyakarta".

\section{METODE PENELITIAN}

Objek penelitian ini adalah BMT Batik Mataram Wirobrajan Yogyakarta karena berdasarkan data observasi, jenis pembiayaan yang paling diminati nasa-bah di 
BMT Batik Mataram adalah pembiayaan musyarakah. Oleh karena itu perlu dipastikan bahwa praktik pembiayaan musyarakah yang diterapkan di BMT Batik Mataram sudah sesuai dengan aturan yang berlaku atau belum, untuk meminimalisasi pihak yang dirugikan, baik dari pihak BMT ataupun nasabah. Penelitian menggunakan data primer yang terdiri dari hasil wawancara dan observasi. Kemudian menggu-nakan data sekunder yang terdiri rincian tabel angsuran pembiayaan musyarakah usaha untung angsuran lancar, dan usaha rugi angsuran tidak lancar. Pengum-pulan data menggunakan wawancara dengan mengajukan pertanyaan kepada kepala BMT, marketing, dan nasabah yang berkaitan dengan pembiayaan musyarakah. Metode analisis menggunakan deskriptif analisis, yaitu metode yang digunakan untuk menganalsis suatu hasil penelitian berdasarkan fakta yang tampak seba-gaimana adanya. Analisis menggunakan fatwa DSN-MUI NO.08/DSNMUI-/IV/2000 dan rumus perhitungan bagi hasil pembiayaan musyarakah yaitu;

$$
\text { Profit = pendapatan }- \text { modal - biaya }
$$

\section{HASIL DAN PEMBAHASAN}

Prosedur Pembiayaan Musyarakah di BMT Batik Mataram.

Prosedur pengajuan pembiayaan musyarakah di BMT Batik Mataram dimulai dari calon nasabah mengajukan pembiayaan musyarakah kepada pihak BMT Batik Mataram Wirobrajan Yogyakarta. Selanjutnya pihak marketing menjelaskan bagaimana prosedur dan syarat untuk pengajuan pembiayaan musyarakah. Calon nasabah KEMUDIAN mengumpulkan berkas sebagai syarat untuk pengajuan pembiayaan. Syarat tersebut anatara lain Foto copy KTP suami isteri, Kartu keluarga, Surat menikah daN Akta anak. Setelah berkas sudah dikumpulkan kepada pihak BMT calon nasabah mengisi formulir pembi-ayaan musyarakah. Selanjutnya bagian marketing akan melakukan survey jaminan, dan hal-hal berkaitan dengan usaha yang akan dijalankan oleh calon nasabah. Setelah dianggap layak dan disetujui oleh pihak yang berwenang untuk memutuskan pemberian pembiayaan, maka dilakukan akad dan pencairan modal untuk dipinjamkan kepada nasabah. Lama untuk pencairan sekitar satu mingguan. Jika tidak disetujui maka pengajuan pembiayaan tersebut tidak dapat dilanjutkan.

Ketentuan untuk prosedur palaksanaan pembiayaan musyarakah yang diberlakukan oleh BMT Batik Mataram yaitu pernyataan ijab dan qabul harus di pahami dan ada kedua belah pihak atau antara pihak BMT dan nasabah saling memahami kontrak pembiayaan musyarakah yang akan dilaksanakan. Pihak
BMT dan nasabah memahami tentang prosedur pembiayaan musyarakah, akad yang akan dilaksanakan, kemudian masing-masing mitra harus memberikan kontribusi modal dan pekerjaan. Dan salah satu mitra diberikan wewenang lebih untuk mengelola usaha musyarakah. Masing-masing mitra harus memenuhi syarat obyek akad antara lain: modal adalah uang atau barang yang dapat diuangkan yang nilainya adalah sama, masing-masing mitra harus memberikan kontribusi kerja. Untuk menghindari penyimpangan pihak BMT meminta jaminan berupa surat berharga. Keuntungan dari kegiatan usaha musyarakah tidak menjadi dasar bagi hasil anatar BMT dan nasabah, untuk bagi hasil BMT menentukan dari besaran pinjaman pokok yaitu sebesar 2\% dari pinjaman pokok. Ketika terjadi kerugian, maka pihak BMT akan melakukan akad ulang dengan diawali dengan musyawarah untuk menentukan penyelesaian dari angsuran yang masih menjadi kewajiban nasabah. Penyelesaian tersebut dilakukan de-ngan menyesuaikan jumlah angsuran yang mam-pu dibayarkan oleh nasabah, banyak kemung-kinan akan ditambah pula tempo pelunasanya. Tentang biaya operasional untuk pembiayaan musyarakah ditanggung bersama antara BMT dan nasabah. Ketika terjadi persengketaan dan sulit mendapat kesepakatan, maka penyelesaian akan dilakukan melalui Badan Arbitrasi Syariah.

Perhitungan Bagi Hasil Pembiayaan Musyarakah.

Dasar perhitungan bagi hasil musyarakah di BMT Batik Mataram Wirobrajan adalah besaran pokok pinjaman dari nasabah dikali $2 \%$. Kebijakan tersebut ada karena nasabah yang memang meminta untuk ditetapkan besaran angsuran setiap bulanya dan sebelumnya dari marketing BMT sudah menjelaskan bagaimana perhitungan untuk dasar bagi hasil pembiayaan musyarakah. Alasan dari nasabah antara lain karena mereka merupakan usaha yang relative sederhana, dan tidak begitu membutuhkan perincian laporan keu-angan, mereka tidak selalu dan tidak semua pengelola usaha dapat menyediakan laporan keuangan sebagai dasar perhitungan keuntungan yang didapatkan bagi pihak BMT untuk menen-tukan besaran bagi hasil. Kemudian karena bebe-rapa nasabah tersebut tidak berkenan jika berda-sarkan keuntungan, ketika mendapatkan keuntu-ngan yang lebih maka nasabah akan menyetor dengan besaran uang yang lebih kepada BMT Batik Mataram Wirobrajan. Perhitu-ngan bagi hasil di BMT Batik Mataram Wirobrajan Yogyakarta:

Bagi hasil $=$ pinjaman pokok $\times 2 \%$ 
Dengan pencatatan akuntansi:

Jika nasabah dapat membayar angsuran pokok dan margin bagi hasil:

Kas

$\begin{array}{ll}\text { Pembiayaan musyarakah } & x x x \\ \text { Bagi hasil musyarakah } & x x x\end{array}$

Jika nasabah tidak dapat membayar angsuran pokok dan bagi hasil (usaha rugi):

Dalam hal ini akan dilakukan rescheduling (perpanjangan jangka waktu pembiayaan) yang sebelumnya sudah dilakukan musyawarah antara BMT dan nasabah dalam hal seberapa besar kemampuan nasabah yang dapat dipenuhi agar memperlancar kembali angsuran setiap bulan. akadnya adalah menggunakan akad Qardh yang berarti tolong menolong.

Kemudian pencatatan jurnalnya:

Pembiayaan dianggap lunas terlebih dahulu

$\begin{array}{cc}\text { Kas } & x x x \\ & \text { Pembiayaan musyarakah } \\ \text { Bagi hasil musyarakah } & x x x\end{array}$

Pencairan pembiayaan ulang dengan angsuran sesuai kemampuan nasabah (Qardh)

$$
\begin{aligned}
& \text { Qordhul Hasan } \\
& \text { Kas } \\
& x X X \\
& X X X
\end{aligned}
$$

\section{Kesesuaian Pelaksanaan Pembiayaan Musyarakah dengan Prinsip Syariah Berdasarkan Fatwa DSN-MUI No.08/DSN-MUI/IV/2000.}

Kesesuaian prosedur pembiayaan musyarakah de-ngan fatwa DSN-MUI No.08/DSN-MUI/-IV/2000 di BMT Batik Mataram. Adapun ketentuan dari DSN-MUI tentang pembiayaan musyarakah yaitu: Pernyataan ijab dan qabul harus dinyatakan oleh para pihak untuk menunjukkan kehendak mereka dalam mengadakan kontrak (akad), dengan memperhatikan penawaran dan penerimaan harus secara eksplisit menunjukkan tujuan kontrak (akad), penerimaan dari penawaran dilakukan pada saat kontrak, dan akad dituangkan secara tertulis, melalui korespondensi, atau dengan menggunakan cara-cara komunikasi modern. Pihakpihak yang berkontrak harus cakap hukum, dan memperhatikan kompeten dalam memberikan atau diberikan kekuasaan perwakilan, setiap mitra harus menyediakan dana dan pekerjaan, dan setiap mitra melaksanakan kerja sebagai wakil, setiap mitra memiliki hak untuk mengatur aset musyarakah dalam proses bisnis normal, setiap mitra memberi wewenang kepada mitra yang lain untuk mengelola aset dan masing-masing dianggap telah diberi we- wenang untuk melakukan aktifitas musya-rakah dengan memperhatikan kepentingan mitranya, tanpa melakukan kelalaian dan kesalahan yang disengaja, dan seorang mitra tidak diizinkan untuk mencairkan atau menginvestasikan dana untuk kepentingannya sendiri.

Obyek akad berupa modal yang diberikan harus uang tunai, emas, perak atau yang nilainya sama. Modal dapat terdiri dari aset perdaga-ngan, seperti barang-barang, properti, dan sebagainya. Jika modal berbentuk aset, harus terlebih dahulu dinilai dengan tunai dan disepakati oleh para mitra. Para pihak tidak boleh meminjam, meminjamkan, menyumbangkan atau menghadiahkan modal musyarakah kepada pihak lain, kecuali atas dasar kesepakatan. Pada prinsipnya, dalam pembiayaan musyarakah tidak ada jaminan, namun untuk menghindari terjadinya penyim-pangan, LKS dapat meminta jaminan.

Obyek akad berupa kerja berupa partisipasi para mitra dalam pekerjaan merupakan dasar pelaksanaan musyarakah akan tetapi, kesamaan porsi kerja bukanlah merupakan syarat. Seorang mitra boleh melaksanakan kerja lebih banyak dari yang lainnya, dan dalam hal ini ia boleh menuntut bagian keuntungan tambahan bagi dirinya. Setiap mitra melaksanakan kerja dalam musyarakah atas nama pribadi dan wakil dari mitranya. Kedudukan masingma-sing dalam organisasi kerja harus dijelas-kan dalam kontrak.

Obyek akad berupa keuntungan harus dikuantifikasi dengan jelas untuk menghindarkan perbedaan dan sengketa pada waktu alokasi keuntungan atau penghentian musyarakah. Setiap keuntungan mitra harus dibagikan secara proporsional atas dasar seluruh keuntungan dan tidak ada jumlah yang ditentukan di awal yang ditetapkan bagi seorang mitra. Seorang mitra boleh mengusulkan bahwa jika keuntungan melebihi jumlah tertentu, kelebihan atau prosentase itu diberikan kepadanya. Sistem pembagian keuntungan harus tertuang dengan jelas dalam akad.

Obyek akad berupa Kerugian harus dibagi di antara para mitra secara proporsional menurut saham masing-masing dalam modal.

Obyek akad berupa Biaya Operasional dan Persengketaan yang dibebankan pada modal bersama. Jika salah satu pihak tidak menunaikan kewajibannya atau jika terjadi perse-lisihan di antara para pihak, maka penyelesaiannya dilakukan melalui Badan Arbitrasi Syariah setelah tidak tercapai kesepakatan melalui mu-syawarah. 
Kesesuaian perhitungan bagi hasil pembiayaan musyarakah dengan Fatwa DSN-MUI No.08/D-SNMUI/IV/2000 di BMT Batik Mataram.

Sesuai dengan fatwa No.08/DSN-MUI/IV/2000 tentang pembiayaan musyarakah di dalamnya dibahas tentang ketentuan keuntu-ngan musyarakah yang menjadi dasar perhitu-ngan bagi hasil usaha musyarakah. Persamaan perhitungan keuntungan dari DSN-MUI No.08/DSN-MUI/IV/2000:

Keuntungan (Profit Sharing):

Profit = pendapatan - modal - biaya

Arwani (2016) pencatatan akuntansi pembiayaan musyarakah (adopsi dari IFRS) adalah:

Jika untung (pembiayaan musyarakah)

Kas/piutang bagi hasil

$x X X$

Pend. bagi hasi

$x x x$

Pada saat pembayaran piutang

Kas

Jika rugi

Piutang bagi hasil

$x X X$

$x X X$

Kerugian

Pem. musyarakah
Analisis Kesesuaian Praktik Pembiayaan Musyarakah di BMT Batik Mataram Wirobrajan Yogyakarta terhadap Fatwa No.08/DSN-MUI/IV/2000.

Prosedur pembiayaan musyarakah di BMT Batik Mataram Wirobrajan Yogyakarta belum sepenuhnya dilaksanakan sesuai dengan DSN-MUI fatwa No.08/DSN-MUI/IV/2000. Ketidaksesuaian tersebut pada pembagian resiko kerugian usaha musyarakah. Pada BMT Batik Mataram perlakuan kerugian tersebut dilakukan reschedulling dengan melakukan akad Qardh, jadi nasabah akan tetap mengangsur berapa kekurangan angsuran akibat kerugian usaha dengan kesepakatan jumlah angsuran sesuai kemampuan nasabah. Hal ini tidak sesuai dengan DSN-MUI yang seharusnya ketika terjadi kerugian maka kerugian tersebut ditanggung kedua mitra sebesar kontribusi modal, kerugian tersebut akan memengaruhi jumlah modal dari BMT ataupun nasabah yang akan berpengaruh pada bahi hasil atau rugi selanjutnya.

Tabel 1. Analisis Kesesuaian Praktik Pembiayaan di BMT Batik Mataram Wirobrajan terhadap Fatwa No. Musyarakah 08/DSN-MUI/IV/2000

\begin{tabular}{cccc} 
No. & Fatwa & Pembiayaan Musyarakah BMT Batik & Belum sesuai/ \\
& No.08/DSN-MUI/IV/2000 & Mataram Wirobrajan & Sesuai \\
\hline
\end{tabular}

1. Pernyataan ijab qabul harus dinyatakan Pernyataan ijab qabul harus dipa-hami oleh para pihak untuk menunjukkan ke- dan ada kedua belah pihak atau antara hendak mereka dalam kontrak. Pena- pihak BMT dan nasabah saling mewaran, penerimaan, dan penawaran dila- mahami kontrak pembiayaan musya-

Sesuai kukan pada saat kon-trak dan dituangkan secara tertulis.

2. Pihak yang berkontrak harus cakap Pihak BMT dan nasabah memahami hukum dan memerhatikan kompetensi tentang kekuasaan, setiap mitra harus menyediakan dana dan pekerjaan, serta setiap mitra melaksanakan kerja sebagai wakil. Setiap mitra memberi wewenang kepada mitra lain untuk mengelola aset dan masing-masing dianggap telah diberi wewenang untuk melakukan aktifitas musyarakah.

3. Modal yang diberikan harus uang tunai, emas, perak, atau yang nilainya sama. Para pihak tidak boleh menggunakan modal musyarakah untuk dipinjam, dipinjamkan, disumbangkan atau dihadiahkan kecuali ada kesepakatan. LKS boleh meminta jaminan untuk menghindari penyimpangan. tentang prosedur pembiayaan musyarakah, akad yang akan dilaksanakan, kemudian masing-masing mitra harus memberikan kontribusi modal dan pekerjaan. Dan salah satu mitra diberikan wewenang lebih untuk mengelola usaha musyarakah.

Masing-masing mitra harus memenuhi syarat obyek akad antara lain: modal adalah uang atau barang ya-ng dapat diuangkan yang nilainya adalah sama, masing-masing mitra harus memberikan kontribusi kerja. Untuk menghindari penyimpangan pihak BMT meminta jaminan berupa surat berharga.
Sesuai

Sesuai 
Tabel 2. Analisis Kesesuaian Praktik Pembiayaan di BMT Batik Mataram Wirobrajan terhadap Fatwa No. Musyarakah 08/DSN-MUI/IV/2000 (Lanjutan)

\begin{tabular}{llll}
\hline No. & Fatwa & Pembiayaan & Musyarakah \\
No.08/DSN-MUI/IV/2000 & BMT & Batik & $\begin{array}{c}\text { Belum sesuai/ } \\
\text { Sesuai }\end{array}$ \\
\hline
\end{tabular}

4. Masing-masing mitra memberikan ko- Masing-masing mitra memberikan kontribusi kerja akan tetapi kesamaan porsi ntribusi kerja, yaitu BMT melakukan kerja bukan merupakan syarat. monitoring usaha musyarakah setiap bulannya dan selebihnya dalam pengelolaan usaha nasabah yang akan meSesuai ngelola (nasabah me-mberikan kontribusi kerja lebih banyak daripada BMT).

5. Keuntungan harus dikuantifikasikan Keuntungan dari kegiatan usaha dengan jelas, setiap keuntungan mitra musyarakah tidak menjadi dasar ba-gi harus dibagikan secara proporsional atas hasil antara BMT dan nasabah. Bagi dasar seluruh keuntungan dan tidak ada hasil ditentukan di awal akad yaitu jumlah yang ditentukan di awal yang di- sebesar $2 \%$ dari besaran pinjaman potetapkan bagi seorang mitra. Seorang kok. Hal tersebut karena ada bebe-rapa mitra boleh mengusulkan jika keuntung- pertimbangan dari na-sabah dan BMT. an melebihi jumlah tertentu, kelebihan tersebut diberikan kepadanya. Sistem pembagian keuntungan harus tertuang jelas dalam akad.

6. Kerugian harus dibagi di antara para mitra secara proporsional menurut saham masing-masing dalam modal.

Saat terjadi kerugian pihak BMT akan melakukan akad ulang resechedulling dengan besaran angsuran yang lebih sedikit dan waktu yang lebih lama sesuai dengan kemampuan nasabah.

\begin{tabular}{ll}
\hline 7. & Biaya operasional ditanggung kedua mi- \\
tra.
\end{tabular}

Kemudian perhitungan bagi hasil yang dilaksanakan di BMT Batik Mataram Wirobrajan Yogyakarta belum sesuai dengan fatwa No.08/D-SNMUI/IV/2000. Perhitungan bagi hasil yang diterapkan yaitu didasarkan pada $2 \%$ dari pinjaman pokok, dengan rumus:

Bagi hasil= pinjaman pokok $\times 2 \%$ persamaan tersebut tidak sesuai dengan ketentuan yang ditetapkan DSN-MUI yang menyebutkan bahwa bagi hasil dari kegiatan Lem-baga Keuangan Syariah (LKS) untuk pembiayaan musyarakah adalah didapatkan dari keuntungan.

\section{KESIMPULAN}

Prosedur pembiayaan musyarakah yang dilaksanakan di BMT Batik Mataram belum seluruhnya
Biaya operasional ditanggung kedua mitra.

Sesuai

Ketika terjadi perselisihan dan tidak dapat diselesaikan melalui musyawarah maka diselesaikan melalui Badan Arbi-

Sesuai trasi Syariah.
Belum sesuai

sesuai dengan Fatwa DSN-MUI NO.08/DSN-MUI/IV/2000. Ketidaksesuainya adalah pada saat pembagian kerugian, pihak BMT menetapkan bah-wa jika terjadi kerugian, akan dilakukan reschedulling dengan meggunakan akad Qardh. Perhitungan bagi hasil atau bagi untung pembiayaan mu-syarakah di BMT Batik Mataram belum sesuai dengan Fatwa No.08/DSN-MUI/IV/2000. Pada BMT Batik Mataram dasar pengenaan untuk perhitu-ngan bagi hasil adalah dari besaran pokok pinja-man yang diajukan nasa-bah. sedangkan pada DSN-MUI menjelaskan bah-wa dasar pengenaan bagi hasil pembiayaan musyarakah adalah dari keuntu-ngan. Keterbatasan penelitian ini adalah hanya berfokus pada pembiayaan musyarakah, oleh karena itu untuk penelitian selanjutnya dapat memperluas area penelitian berdasarkan jenis pembiayaan dan objek penelitian. 


\section{DAFTAR PUSTAKA}

Agustha, Ilham Nur. 2014. Perbedaan Pembiayaan Model bagi Hasil dan Non Bagi Hasil terhadap Profitabilitas dan Resiko (Studi kasus BMT Amanah Ummah). Jurnal Ekonomi Syariah Teori dan Terapan. Vol. 1, No. 4, April

Ascarya. 2015. Akad \& Produk bank Syariah. Jakarta. Rajawali Pers.

Arwani agus. 2016. Akuntansi Perbankan Syariah: dari Teori ke Praktik. [Online] Tersedia: https://books.google.co.id/books [21 Juli 2018]

Fatwa MUI. 2004. FATWA MAJELIS ULAMA INDONESIA Nomor 1 Tahun 2004 Tentang BUNGA (INTEREST/FA'IDAH). [Online] Tersedia: http://muijatim.org/wpcontent/uploads/2016/09/BungaInterestFaidah_2004.pdf [12 April 2018]

DSN-MUI. 2000. Fatwa Dewan Syari'ah Nasional Nomor 08/DSN-MUI/IV/2000 Tentang Pembiayaan Musyarakah. [Online] Tersedia: https://tafsirq.com/fatwa/dsnmui/pembiayaan-musyarakah [12 April 2018]

DSN-MUI. 2000. Fatwa Dewan Syari'ah Nasional Nomor 15/DSN-MUI/IX/2000 Tentang prinsip Bagi Hail Usaha Lembaga Keuangan Syariah. [Online] Tersedia: https://tafsirq.com/fatwa/dsnmui/prinsip-distribusi-hasil-usaha-dalamlembaga-keuangan-syariah-1 [15 Juli 2018]

Hestanto. 2016. Pengertian BMT (Baitul Maal wa Tamwil). [Online] Tersedia: http://www.hestanto.web.id/bmt/ [13, Desember 2017]

Nugraheni. 2010. "Asas Kesetaraan dalam Akad Pembiayaan Musyarakah pada bank Syariah di Yogyakarta". Mimbar Hukum. Vol 22, hal: 1200

Wulaningrum, P. D., \& Nisa, A. (2018). Praktik Penerapan Akad Murabahah Dalam Pembiayaan Pensiun di Bank Syariah Mandiri. Jati: Jurnal Akuntansi Terapan Indonesia, 1(1), 38-45.

Riadi, Muchlisin. 2014. Baitul Maal Wat Tamwil (BMT). [Online] Tersedia: https://www.kajianpustaka.com/2014/02/bait ul-maal-wat-tamwil-bmt.html [11 April 208]
Sriyana, Jaka. 2013. "Peran BMT dalam Mengatasi Kemiskinan di Kabupaten Bantul. Jurnal Penelitian Sosial Keagamaan. Vol. 7, No. 1, Juni.

Wiwoho, Jamal. 2014. "Peran Lembaga Keuangan Bank dan Lembaga Keuangan Bukan Bank dalam Memberikan Distribusi Keadilan Bagi Masyarakat". Jurnal Wiwoho. Masalahmasalah Hukum. Vol. 43, No. 1, Januari. 